\title{
Husserl. Elementos de autorreflexión filosófica
}

Javier Corona Fernández

Universidad de Guanajuato

\section{Resumen}

Este ensayo presenta algunos elementos de la autorreflexión filosófica propuesta por la fenomenología a partir de ciertos puntos de análisis como la denuncia acerca del olvido del mundo de la vida; el señalamiento en torno a la necesidad de una fundamentación humana de la ciencia; la acusación de que la teoría está volcada sobre la facticidad y la concepción de la filosofía como autorreflexión de la humanidad. Tópicos que han colocado a la fenomenología como una de las corrientes protagonistas de la filosofía contemporánea.

Palabras clave: Autorreflexión, fenomenología, mundo de la vida, intencionalidad.

\section{Abstract}

This work presents some elements of philosophical self-reflection suggested by phenomenology from some points of analysis as the complaint about the neglect of the life world; the indication about the 
necessity of a human foundation Science; the charge that the theory is overturned on the factuality and the conception of philosophy as self-reflection of humanity. Topics that have placed phenomenology as one of the protagonists currents of contemporary philosophy.

Keywords: Self-reflection, phenomenology, lifeworld, intentionality.

En la era de la informatización escuchamos el eco de teorías que putacional al que es preciso saturar de datos. Esto último es un lugar común en las discusiones de nuestro tiempo, sin embargo, el tema abre la reflexión hacia una propuesta como la de Husserl, que representa una opción para pensar alternativas ante la imposición de aquella tendencia reduccionista que persigue insistentemente la destrucción temática y vivencial del ser humano, rebajado al rango de "dispositivo inteligente" pero sin historia, sin moral, sin intereses legítimos que le lleven hacia la consecución de una vida plena. En la reflexión sobre el sentido de la existencia humana que en el siglo XXI podría tener lugar, las tesis de Husserl responden a una problematización del mundo contemporáneo que se mantiene hasta nuestros días.

Si bien podemos probar la actualidad del pensamiento de Husserl enfrentándolo a situaciones como la arriba descrita, evidentemente sus planteamientos se enriquecieron aun más al salir a la luz sus escritos y con la publicación de los estudios críticos que le siguieron en la segunda mitad del siglo XX, momento en que la fenomenología resurge, sobre todo a raíz del auge de la hermenéutica. Circunstancia que ayuda a que la fenomenología se asiente en el panorama filosófico actual, al grado de que se habla de una nueva escuela fenomenológica o de un nuevo Husserl, que se sitúa por encima de la imagen convencional de los manuales de filosofía.

Esta actualidad quizá se explique porque la fenomenología es la corriente que se aboca a la comprensión de la vida cotidiana en 
contraste con la tradición moderna que tiene como horizontes el conocimiento, la historia o la práctica social. La fenomenología -y posteriormente la filosofía del siglo XX-, tematiza el mundo de la vida y desde ese marco emplaza la fundamentación de la ciencia y de las prácticas teóricas. Pero la fenomenología intenta una profunda transformación en el pensamiento, yendo, tal como señalan los propios fenomenólogos, más allá de la verborrea en que han caído los filósofos y sus sistemas carentes de fundamento real. El propósito de los fenomenólogos ante esta verborrea inútil en que han caído los sistemas filosóficos según su opinión, consiste en el retorno a las cosas mismas. Esta pretensión viene a rodear a la fenomenología de un cierto ambiente de perplejidad, ya que su circunstancia histórica tira más bien hacia la anulación de estatutos incontrovertibles, hacia la recusación de todo intento filosófico que se anuncie como sistemático y esencial. En el contexto del giro anti-metafísico, la fenomenología nos induce a replantear la problemática propia de la filosofía partiendo de lo inmediatamente evidente, de aquello que resista la duda más radical. Puesto que la fenomenología se presenta como ciencia rigurosa, su investigación intenta describir los modos típicos en que las cosas y los hechos se manifiestan ante la consciencia. El análisis de estos modos típicos es la tarea propia de la fenomenología: indagar acerca de qué es lo que la consciencia trascendental concibe por percepción, conocimiento, justicia, amor, religiosidad. La fenomenología estudia las significaciones, las regiones de esencias y el sentido de la consciencia, su intencionalidad.

Entre tales regiones de significación aparece precisamente la ciencia, actividad que con fuerza demoledora se ha impuesto en el mundo de los últimos siglos, hasta convertirse en un rasgo insustituible de nuestro tiempo. En la esfera política, la ciencia ha sido tomada también como coto reservado e instrumento de dominación, lo que ha propiciado urgentes advertencias en contra de este 
estado de cosas que la han llevado a su reificación. Paralelamente, en el plano teórico la ciencia postuló una absolutización del conocimiento de manera muy clara desde finales del siglo XIX, para el siglo XX la tarea primordial de la fenomenología consistió en contrarrestar la absolutización en que la ciencia ha caído a partir de entonces. De esta manera, la filosofía ha de buscar no el conocimiento sino el pensamiento, reconociendo que el problema de lo real sólo puede abordarse desde la perspectiva humana. Al ser expresión humana, la filosofía es inmanente, participa del destino del hombre y en este sentido alcanza una importante redefinición en la obra de Husserl: la filosofía no debe buscar lo trascendente como hace la religión pero tampoco ocuparse de hechos como procede la ciencia, la filosofía debe abrazar la terrenalidad y dejar de lado la metafísica. Este carácter antimetafísico del pensamiento husserliano lo instala en el contexto del siglo XX pero desde una visión propia, que identifica como metafísicas aquellas concepciones dualistas que plantean por un lado una realidad fundante y por otro una realidad fundada, o la apelación a criterios absolutos que den cuenta de manera definitiva de la realidad. Con este deslinde, la fenomenología ha permitido sin duda pensar en otros términos la problemática acerca de lo real al suscribir que aquel dualismo que apunta a definir la realidad, ha ocasionado un falso problema, pues lo real fue considerado como si fuera una cosa, un ente.

Husserl pretende una transformación de la filosofía que recupere sus problemas básicos pero situándolos más allá de la metafísica, pensando el mundo como acaecer y no bajo la idea de una simple combinación de entes. Como punto de partida para la reconstrucción de la filosofía -que involucra también a la propia ciencia del hombre-, Husserl emprende una crítica al psicologismo, iniciativa que en la segunda mitad del siglo XIX representó uno de los ejes principales del positivismo. El psicologismo, dice Husserl, traza una formulación del hombre principalmente como un organismo 
biológico, explicable a partir de circunstancias exteriores a él, por ello, la mente humana es vista como si fuera un pliegue de dicha exterioridad, convirtiendo al ser humano en mera facticidad. En la crítica al psicologismo se expresan problemas y conceptos importantes, los cuales giran en torno a uno de los intereses teóricos más significativos para el trabajo crítico de la fenomenología: la elucidación de la consciencia en un mundo concebido principalmente bajo el imperio de los hechos.

La fenomenología nos propone entonces no pensar lo real, el hombre o el mundo, del mismo modo que se procede con las cosas; antes bien, podemos empezar a delinearlos si nos percatamos de que los elementos del problema no están ya ahí dispuestos, no son simplemente dados. El mundo, lejos de determinarse en fórmulas, es concebido por la fenomenología como un acaecer múltiple, donde el interés central radica en la observación de que el mundo se abre al hombre. Por lo tanto, es necesario no caer en la entificación como hace la metafísica; lo procedente en este caso es pensar al mundo y al hombre, problemas siempre urgentes para la filosofía, no como existiendo independientemente el uno del otro sino en una interacción permanente, que comprende lo real como acaecer. Al encarar el estado que guarda la reflexión en el siglo $\mathrm{XX}$, en el diagnóstico de Husserl la filosofía se encuentra en una encrucijada: no puede seguir siendo metafísica, pero la ciencia no parece ser un mejor camino. La filosofía tendrá que renunciar a la metafísica mas cuidarse también de caer en el cientificismo; la filosofía no debe plantearse ya qué es el conocimiento, el alma o el mundo tal como lo viene haciendo a lo largo de su tradición. Al preguntar por el ente, dice Aristóteles, estamos preguntando por la sustancia; la reflexión de nuestro tiempo, propone Husserl, debe remontarse por encima de dicha estimación y preguntar por lo real, no por las sustancias o esencias de la realidad en el sentido metafísico apuntado, ni por la cosificación y facticidad que ca- 
racteriza a las elaboraciones positivistas de la modernidad. Pero la fenomenología se enfrenta con una gran dificultad, debido a que desde la antigüedad lo real fue confundido con las cosas, con las sustancias o con los entes.

Intentando superar tal reduccionismo, la fenomenología declara, en primer lugar, la necesidad de ir a las cosas mismas; distinguir su verdadera dimensión, encontrar una forma de hacer referencia a los hechos que sea nueva, que por lo tanto redefina la noción misma de hecho. La fenomenología se distingue de la tradición porque muestra la insuficiencia de seguir entendiendo por "hechos" aquello que sucede en las "cosas". Para Husserl los hechos son fenómenos, subjetivos y objetivos a la vez, los hechos no son los objetos como tales sino nuestra percepción de ellos, un hecho es por lo tanto una abstracción. El objeto, lejos de ser un punto de partida, debe más bien plantearse como una síntesis, el origen de la metafísica es suponer que lo real se compone de cosas que se relacionan, la pregunta sobre lo real nada tiene que ver con cosas. Por el contrario, para Husserl sólo desde la dimensión humana puede asumirse cualquier elaboración, los objetos siempre son pensados en relación con alguien, más que preguntar sobre la realidad, la verdadera pregunta sería cómo se nos aparece el mundo, cómo nos sale al encuentro. De este modo, la tarea de la fenomenología consistió y consiste todavía en crear un dispositivo metodológico para describir el complejo entramado de fenómenos que nos sale al encuentro, tal dispositivo habrá de situarse en el mundo de la vida, dimensión a la que pertenece la filosofía como reflexión sobre las condiciones en que se da la experiencia cotidiana, científica, estética, moral, religiosa o de cualquier otra índole. Mientras las ciencias buscan explicaciones, la filosofía busca comprender aquellos problemas que son los más acuciantes para el hombre, el cual en nuestro tiempo se siente a merced del destino: los problemas del sentido y de la falta de sentido de la existencia humana en su conjunto. 
Pero la fenomenología guarda también una relación importante con la tradición filosófica preocupada por el método, de ahí que simultáneamente a la crítica del estado que guarda la especulación metafísica, la fenomenología proponga su propio proceder: todo comportamiento humano tiene una tendencia, una intencionalidad, un sentido que la consciencia toma. De tal modo que los fenómenos son pensados como síntesis de múltiples intenciones, estas intenciones tienen su despliegue en la vivencia, entendida como un estado en que nosotros como consciencia nos encontramos con el mundo.

Para mejor delinear el objetivo de su propuesta filosófica, Husserl toma como ejemplo la actitud natural del hombre. Esta actitud está constituida por ciertas convicciones, que sin duda le son útiles para desenvolverse en la vida cotidiana, la primera de ellas es que vivimos en un mundo de cosas existentes, pero esta certeza no tiene una evidencia incuestionable, razón por la cual bien podemos ponerla entre paréntesis. No se trata de dudar de las cosas, esto podría parecer muy ingenuo, de lo que se trata es de dejarlas de lado, de no utilizarlas como fundamento de la filosofía. Si el filósofo aspira a una ciencia rigurosa, debe buscar aquello que resulte evidente sin duda alguna, que resista la epojé. La convicción ingenua de que el mundo existe ahí, no permite acceder a ninguna proposición filosófica, puesto que la existencia del mundo, fuera de la consciencia que lo capta, no es un absoluto indudable. Husserl considera que en su condición de hombre, el filósofo cree en la existencia del mundo, pero cuando reflexiona como filósofo no puede tomar dicha creencia como punto de partida. Aunque tampoco puede partir de los resultados de la investigación científica, debido a que las ciencias interpretan los datos de la experiencia común y los aceptan ingenuamente, sin preguntarse si estos resisten a la acción de la epojé, sin detenerse a pensar si tales certezas constituyen o no realidades indudables. La epojé permite a la postre ubicar en su sitio real la racionalidad formulada en las ciencias de la naturaleza. 
La fenomenología se ha constituido por estos señalamientos en un punto de referencia obligado para toda investigación filosófica que considere el panorama del siglo XX, donde la condición humana se revela con características específicas y demandante de una perspectiva peculiar. En este sentido, el prejuicio de concebir a las cosas con existencia independiente ha ocasionado que perdamos de vista que los demás entes están en el mundo, mientras que nosotros nos encontramos con él en cada caso y en ciertas situaciones. Los hombres en cada instante existimos de un modo diferenciado, el mundo nos desafía, nos obliga a confrontarlo a lo largo de nuestra experiencia de vida. La esfera del tiempo aparece aquí con singular importancia porque la noción de mundo enmarca los instantes vividos, pero cuya vivencia se da también con la certeza de que se va a la muerte, por esto cada momento de nuestra vida es especial, no sabemos cuándo sobrevendrá el desenlace final para cada uno, a esto se debe que nuestra existencia esté fijada por el pasado. Somos nuestra historia, no podemos vivir el instante presente como tal, sino siempre en función de lo que ha sido, en una unidad histórica vital. Por esta condición ontológica, toda visión fragmentaria del mundo o del individuo por separado no puede sostenerse, puesto que en cada instante experimentamos la vida como totalidad y actuamos siempre como un todo en nuestras vivencias. Una vivencia es esa condición en que sabemos que nos estamos jugando la existencia entera, cada que actuamos o experimentamos algo, al mismo tiempo nos experimentamos a nosotros mismos como sabiendo que somos nosotros.

Ante el hallazgo de nuestra propia circunstancia, Husserl propone hacer una reducción y seńalar que el objetivo primero que persigue la epojé es desocultar, atacar la creencia según la cual el mundo está ahí y su existencia no plantea ningún problema, "En todas partes el ser verdadero es un fin ideal, una tarea de la episteme, de la 'razón', y opuesto al pretendido ser 'obvio' que la doxa da como meramente supuesto en forma no problemática” (Husserl, 1984: 18). 
Considerando el mundo que se abre en el siglo XX, la fenomenología pregunta: ¿cuál es el significado y finalidad del mundo para mí y para los demás sujetos, si en un tiempo tan atormentado como éste nos sentimos a merced del destino? Esta pregunta no puede ser encarada invocando direcciones específicas, al no haber un destino predeterminado, la unica salida es buscar dotar de sentido a nuestra existencia en lo individual. Vivimos en primera persona, somos presentes a nosotros mismos cada que actuamos, y este drama de nuestro actuar nos indica que nosotros no transcurrimos en el tiempo, somos tiempo.

Por este motivo lo humano sólo es la vivencia, la vivencia es el modo de ser del hombre; nuestros instantes no son suma de estímulos sino vivencias que se dan en el horizonte del tiempo. En la fenomenología el tiempo es una esfera de problemas perfectamente cerrada, pero advierte Husserl, una esfera de excepcional dificultad. Esto se debe a que por su propia naturaleza es difícil de asir, fijemos nuestra atención por ejemplo en el ahora actual, vemos que éste se esfuma y se convierte en un "hace un momento" y a su vez el "hace un momento" en un "hace un momento" de "hace un momento" y así para cada nuevo "ahora" que se adhiera. De manera que la corriente de las vivencias es una unidad infinita. En este flujo continuo el presente sólo puede captarse como presente vivo, el presente no está en el tiempo, no es un punto del tiempo, constituye el tiempo mismo. Lo que hace importante el planteamiento de Husserl sobre el tiempo es que lo retira de la consideración fisicalista y lo remite al hombre, diciendo que éste no es una sustancia sino temporalidad. La fenomenología se propone comprender la continuidad temporal de la consciencia que articula sus vivencias en un flujo, concediendo en este análisis un cierto primado al pasado, ya que la continuidad puede asegurarse por la retención. Gracias a la cualidad retentiva de la consciencia, el pasado carga el sentido de todas las adquisiciones de la experiencia y las trae al presente que enseguida ha transcurrido. 
Pero la consciencia tiene también un movimiento dirigido a la verdad y ese movimiento se efectúa hacia el porvenir en un proceso en el que el pensamiento fluye. Dicha determinación temporal aparece incluso si intentamos aprehender no la forma de ser de la consciencia, sino -si se nos permite decir-, la de los objetos, puesto que los objetos son siempre síntesis de aspectos que de ellos hemos percibido sucesivamente. De igual modo ocurre con el pensamiento humano individualmente considerado; dada nuestra constitución, no vemos todos los lados del cubo al mismo tiempo, no captamos sus aristas simultáneamente, siempre tenemos presente la relación del todo y las partes, siempre debemos de pasar de un aspecto a otro en este flujo temporal que caracteriza la vida de la consciencia. La consciencia es esa totalidad que se despliega en el mundo de la vida con carácter unitario y sintético, ámbito donde encuentra las evidencias originales, perdidas por completo para el objetivado mundo de las ciencias. Husserl nos recuerda que ese mundo científico de operaciones lógico-objetivas ha olvidado que sus asertos toman su evidencia de aquellas evidencias pre-científicas del mundo de la vida, mundo del que parte cualquier horizonte de significación que pueda plantearse.

Así, frente a la estimación de la ciencia como algo absoluto, ${ }^{1}$ la fenomenología subraya su carácter convencional y la imposibilidad de que pueda efectivamente responder a los problemas más urgentes de nuestro tiempo. Al no tener la capacidad de responder a dichos problemas, la ciencia revela la profunda crisis del proyecto moderno de hombre, proyecto que se ha extraviado desde la fuente misma al postular equivocadamente un enfoque epistemológico determinado para definir su objeto, haciendo del hombre

\footnotetext{
${ }^{1}$ Un autor contemporáneo como Adorno coincide con Husserl cuando dice que es preciso considerar aquello que el conocimiento científico ha despreciado, esto es, lo particular y perecedero, lo que no merece pasar a concepto. Por tal razón es necesario buscar un sentido de racionalidad que ha sido marginado por las ciencias.
} 
un hecho en el mundo e impidiendo la posibilidad de concebirlo como sujeto. Aquí podemos apreciar el principal elemento de la crítica husserliana al psicologismo, el cual no es simplemente una postura epistemológica; en el psicologismo también va implícita una concepción antropológica, cuyo desenlace es la eliminación del hombre como ser racional. Esto además compromete la concepción misma de ciencia, porque si el hombre es visto como un resultado de hechos, no es posible garantizar un lugar para la razón y, concluye Husserl, sin razón, tampoco hay lugar para la ciencia ni para la filosofía. Si lo que caracteriza al hombre es su razón, ésta no puede verse sin más como un hecho en el mundo puesto que en estricto sentido no proviene de los hechos, en la reflexión fenomenológica la razón es irreductible a lo fáctico.

Para el análisis husserliano, aquella postura psicologista es propia de prácticamente toda la actividad científica realizada en Europa en los últimos siglos. Práctica científica que obedece, en última instancia, a todo un espectro de crisis más amplio, tan general que involucra a la totalidad de la cultura de Occidente y al proyecto de hombre que de ahí emana. ${ }^{2}$ Sin embargo, ¿cuál es el origen de este desenlace nada halagüeńo en que se ha transformado el proyecto europeo de cultura? Para Husserl la respuesta a esta cuestión ha de rastrearse no en una cualidad que esta cultura tenga o en algún exceso de cualquier tipo, sino en una carencia. Ciertamente, Husserl considera que la crisis de la filosofía, de las ciencias y de la cultura europea en general, se debe a la poca creencia que se tiene en el proyecto teórico, práctico y político que la Modernidad ha implantado y esta ausencia de confianza o de fe puede a su vez explicarse porque el modelo de hombre y de mundo que le carac-

${ }^{2}$ Este tema fue expuesto inicialmente por Husserl en la conferencia que pronunció en la Asociación de Cultura de Viena en mayo de 1935. Conferencia titulada "La filosofía en la crisis de la humanidad europea”, disertación que posteriormente se convertiría en un libro tan importante como Crisis de las ciencias europeas y la fenomenología trascendental. 
teriza viene configurado en una concepción errónea, al asegurar que el sujeto está anclado en los hechos. En la Crisis de las ciencias europeas nuestro filósofo llega a puntualizar de manera más radical que las aspiraciones histórico-antropológicas generadas en el proyecto de la Modernidad han fracasado porque se parte de una posición epistemológica radicalmente errónea, y esta posición la encarna perfectamente el psicologismo.

A contracorriente de la ola disolutiva posmoderna, para Husserl la tarea crítica de la filosofía consiste en recuperar o restaurar al sujeto racional, estrategia intencionalmente dirigida para enfrentar la crisis del hombre. Por esta razón, hemos encontrado una veta importante en la crítica al psicologismo, empeńado éste, como se dijo, en ver al hombre como un hecho en el mundo. Por consiguiente, en semejante reduccionismo antropológico el hombre nunca podrá concebirse como sujeto del mundo, acotándose las expectativas de la razón al hacerla provenir de los hechos. Pero la razón no es, para la fenomenología, ni un hecho ni una colección de hechos, la razón es una unidad en sí misma. Esta posición teórica le viene a Husserl de sus investigaciones en matemáticas y de las consecuencias filosóficas de ahí desprendidas, que a la postre permitieron a la fenomenología criticar toda postura psicologista en el conocimiento. En efecto, en 1891 Husserl publica la Filosofía de la aritmética, en este libro - a diferencia de las posturas logicistas-, el discípulo de Brentano sostiene la reducción del concepto de número a procesos psíquicos referentes a las actividades de agrupar y contar. La propuesta aquí defendida consistió en señalar que la psicología fundamenta a la matemática, puesto que el número se origina en los actos psíquicos de los hombres. La matemática y la lógica acaban por llegar a conceptos últimos y máximamente elementales, los cuales no son definibles, y lo único que se puede hacer en estos casos es mostrar aquellos fenómenos concretos desde los cuales y a través de los cuales se abstraen dichos conceptos. Para 
Brentano y sus discípulos, en la psicología parecen encontrarse las condiciones fundamentales que explican cualquier elaboración artística, científica, política o moral.

No obstante, la postura inicial que Husserl compartía con Brentano respecto a la consciencia, sufrirá una radical transformación a raíz de las observaciones críticas que hace Frege tocante a los planteamientos contenidos en aquella obra de Husserl. En opinión de Frege, Husserl revela ahí una idea ingenua de número; lo que Frege argumenta en principio es que el concepto de número escapa a cualquier descripción de procesos mentales que precedan a un juicio numérico. Por otra parte, hay que tener también en cuenta que una representación psicológica es siempre particular, empírica y subjetiva. La psicología sólo puede aportarnos juicios de hechos, mientras que los juicios matemáticos son universales, ideales y objetivos a un tiempo. Husserl reflexiona acerca de los señalamientos críticos de Frege y modifica su punto de vista anterior, desligándose de cualquier vínculo con el psicologismo. Así, en las Investigaciones lógicas, Husserl propone que las leyes lógicas son en rigor universales y necesarias, y por lo tanto no pueden depender de leyes o condiciones psicológicas, ya que éstas no son necesarias, sino acaso generalizaciones que han sido obtenidas por inducción. Al interior de la perspectiva psicologista, los hechos de consciencia son fugaces singularidades, reales pero determinadas temporalmente, que surgen y desaparecen. En cambio, la verdad es una idea y, como tal, supra-temporal. Husserl llega a la convicción ahora de que hay proposiciones universales y necesarias, entendidas como condiciones que posibilitan una teoría determinada y que se distinguen de aquellas proposiciones que se obtienen inductivamente a partir de la experiencia. En este giro, el fundador de la fenomenología ha encontrado el camino para definir a la consciencia como una unidad en sí misma, que no se deriva ni de los hechos ni de los procesos psicológicos. La razón es esencialmente consciencia, en este senti- 
do es que la fenomenología vendrá a enfatizar la intencionalidad que le caracteriza. Husserl ha llegado a esta posibilidad de concebir una consciencia en sí, gracias al cambio de perspectiva teórica que realiza en matemáticas. ${ }^{3}$

Como resultado del cambio de perspectiva llevado a cabo por su fundador, el sentido crítico de la fenomenología ha identificado la principal carencia de la filosofía. En las Investigaciones lógicas Husserl indica que la metafísica tradicional ha tenido como origen una visión artística, religiosa o humanista, planteando siempre un absoluto, el cual está encargado de dotar de sentido último a estas elaboraciones; pero a partir de la cientificidad moderna, los hechos se han convertido en este nuevo absoluto, la creencia en los hechos es ahora la nueva metafísica. No obstante, Husserl sabe que la filosofía nunca ha sido un simple diagnóstico de cosas o estados de cosas. En consecuencia, tiene una propuesta a este respecto y la encuentra en el replanteamiento mismo de los problemas fundamentales de la filosofía, tratando de cimentarlos teóricamente desde la fenomenología.

La fenomenología permite sentar las bases conceptuales lo suficientemente sólidas para hacer frente a una empresa de tal envergadura: una nueva revolución filosófica. Esta confianza de Husserl radica en su convicción de que el punto de partida ha de ser siempre la razón desde ella misma, tal como es y tal como ella se genera en su proceso de aprehensión del mundo. Por estos motivos, yendo a la consciencia misma del hombre, la filosofía evita ese extravío propio de la metafísica que ha hecho de los problemas fundamentales de la condición humana meras abstracciones. La tarea que Husserl se propuso fue la de remontar tal anatema, buscando un saber firmemente fundado de modo radical y en todos sus ámbitos,

${ }^{3}$ Es importante llamar la atención en este sentido porque dicha posición teórica, de una conciencia que es en sí misma, puede parecer un resabio de idealismo, como creía Adorno en su trabajo titulado Sobre la metacrítica de la teoría del conocimiento (1986). 
y esto sólo puede alcanzarse a través de la autorreflexión. La autorreflexión permite a la filosofía una exposición de las capacidades humanas que posibilitan el conocimiento, concibiendo al hombre como un sujeto racional que se enfrenta al mundo al que trata de conocer y comprender.

Como sabemos, Husserl está inicialmente interesado en la facultad cognoscitiva de la consciencia y centra ahí el eje de su reflexión, de modo que en el proceso de conocimiento no se trata de clasificar al objeto en cualidades primarias y secundarias, subjetivas y objetivas, o por otra parte en ideas innatas o condiciones a priori de la consciencia. Lo que la fenomenología propone para dar respuesta a la pregunta sobre el ser desde la razón cognoscitiva es, en principio, la plena clarificación de los elementos que aquí intervienen: el conocedor y lo cognoscible. ${ }^{4}$

Pero lo cognoscible no tiene una sola cara, el objeto de conocimiento debe concebirse en un doble matiz: por un lado, como objeto (Objekt), con los rasgos para ser identificable por el conocimiento científico; por otro, como aquel entramado complejo que nos sale al encuentro en el desenlace que es el mundo (Gegenstand). Esta distinción da cuenta de la configuración del objeto de conocimiento y evita el reduccionismo, tarea que es propia de la fenomenología descriptiva, la cual nos explica cómo nuestra consciencia actúa sobre los datos que la percepción proporciona en su ir hacia las cosas. Tal intencionalidad es viable por la condición de posibilidad que la estructura misma de la consciencia tiene de ir hacia las cosas y aprehenderlas. Convergentemente, la exposición

\footnotetext{
4 "Con Husserl el problema epistemológico deja de ser puesto en términos de continente y contenido y, de golpe, desaparece. La consciencia no es ya receptáculo de imágenes o depósito de representaciones: es, por definición, intencional, es decir, apertura a las cosas y visión del mundo. Su conocimiento no es ni puede ser sino un perfeccionamiento de la intuición, Anschauung, pero sin resonancias místico-poéticas, y que se traduciría mejor quizá por 'percepción', con tal que no limite la percepción a la captación por los sentidos." (Robberechts, 1968: 70).
} 
de la condición estructural de la consciencia como intencionalidad es el trabajo explicativo propio de la fenomenología trascendental. La fenomenología entendida en esta segunda acepción, faculta para exponer el origen de la objetividad en la subjetividad trascendental. Husserl define a la consciencia como la trascendentalidad misma gracias a la peculiaridad que tiene de sobrepasar todo lo cósico y "situarse fuera", con este proceder, la fenomenología trascendental elucida la posibilidad de un conocimiento objetivamente válido, un conocimiento que es subjetivo, pero alude a un ser objetivo. Para lograr tal fin es necesario que la fenomenología trascendental realice lo que Husserl llama epojé o reducción eidética, procedimiento efectuado para identificar al yo trascendental.

La epojé es una estrategia metodológica que consiste en poner entre paréntesis los juicios y certezas que la consciencia tiende a crear acerca del objeto, por lo tanto, con esta puesta entre paréntesis lo que se busca es hacer presente el ser, evitando denodadamente los prejuicios. En consecuencia, la reducción fenomenológica apunta a fin de cuentas a recuperar, más allá de las sedimentaciones culturales, utilitarias, ideológicas o lingüísticas, el estrato perceptivo original. La fenomenología ensaya perder el mundo mediante la epojé, para recuperarlo después mediante la autorreflexión.

En la autorreflexión se juega no sólo la recuperación del mundo, viene a darse también con ello una redefinición del hombre, que a la sazón parecía ser tan sólo una especie de navegante inseguro en el centro de un embravecido flujo vivencial. En efecto, la definición del hombre como esta encrucijada de influencias, como el lugar de paso de innumerables interferencias siderales físicas, mentales, orgánicas, sociales e históricas, alcanza con Husserl una propuesta en la que los hombres no seríamos ya descritos como una sustancia sino como tiempo, o mejor dicho, como temporalidad. Por esta razón, la pregunta por lo real nada tiene que ver con objetos, la pregunta sobre qué es la realidad resulta impertinente; la 
verdadera pregunta sería cómo se nos aparece el mundo, cómo nos sale al encuentro. En el horizonte del acaecer es donde la pregunta por lo real adquiere sentido, es decir, en el ámbito de los fenómenos, ya que en cada caso el fenómeno es el encuentro de algo con alguien. Lo cual significa que los objetos y los sujetos existen como resultado del acaecer del mundo y no como su punto de partida. La fenomenología crea un dispositivo metodológico para describir los fenómenos en toda su complejidad, dispositivo en el cual no se pretende hacer una nueva filosofía del sujeto como base explicativa tal como lo venía haciendo la metafísica, para la fenomenología el hombre no es una sustancia sino el punto focal de una inmensa red de fenómenos cuya dimensión se da en la esfera del tiempo inmanente. Para Husserl, en la tradición metafísica era imposible ocuparse del problema del hombre debido a una serie de confusiones en la definición y confrontación entre hombre y mundo, origen de todo dualismo o concepción dicotómica.

La superación de este estado de cosas se encuentra en el replanteamiento mismo de la filosofía, al establecer las bases conceptuales para comprender cómo la consciencia del hombre es y aprehende el mundo. En la dilucidación de este problema se propone como estrategia metodológica la autorreflexión: construir las bases conceptuales desde la propia razón tal como ella es. Por esta vía tenemos acceso a la exposición de la capacidad humana para el conocimiento y, con ello, el momento de situar el horizonte desde el que se puede hablar del hombre desde un punto de vista nuevo, que es, sobre todo, una crítica de toda concepción estática o meramente receptiva de la consciencia humana.

\section{La consciencia en el mundo}

Como suele reiterar Husserl, la consciencia no es un molde que espere ser llenado en cada ocasión, sino aquel devenir temporal 
que en su ir hacia los objetos y retener de ellos sus rasgos esenciales, constituye fenómenos, lo que da oportunidad a la consciencia de desplegarse en diferentes ámbitos. Pero, ¿dónde se encuentra esta consciencia, cómo es posible definirla? Para Husserl es preciso adoptar aquí una posición radical y recurrir nuevamente a la reducción eidética, ${ }^{5}$ la cual es una reconducción de la realidad a las esencias en cada sujeto individual, pues sólo así se puede hablar de la consciencia como unidad del flujo de vivencias. A la autorreflexión acompaña también la encrucijada del yo, problema clásico de la modernidad. No obstante, Husserl abandona la epojé radical y mediante la reducción eidética señala que podemos plantear un ego puro para explicar cómo la consciencia puede conocer el mundo y fundamentar su conocimiento. Gracias a esta perspectiva que la fenomenología constitutiva nos proporciona en torno al ego puro, es posible abrir un horizonte de explicación al problema del sujeto porque en la definición del ego puro intervienen elementos de carácter mundano y de carácter trascendental. Husserl coloca la explicación posible en la unidad del yo y de la experiencia constitutiva del mundo unitario, dado que en la fenomenología constitutiva el ego puro y el yo concreto, empírico-mundano, se unifican en el momento en que yo como consciencia experimento el mundo como perteneciéndome. Visto desde este ángulo, el mundo me pertenece y en esta interacción me constituyo a mí mismo como un ser peculiar e irrepetible. En tal entorno de interacción que es el

5 "Esta epokhé fenomenológica o esta puesta entre paréntesis del mundo objetivo, no nos enfrenta, por tanto, con una nada. Más bien, aquello de lo que nos apropiamos precisamente por este medio o, dicho más claramente, lo que yo, el que medita, me apropio por tal medio, es mi propia vida pura con todas sus vivencias puras y la totalidad de sus menciones puras, el universo de los fenómenos en el sentido de la fenomenología. La epokhé es, así también puede decirse, el método radical y universal por medio del cual yo me capto puramente como yo, y con mi propia vida pura de conciencia en la cual y por la cual es para mí el entero mundo objetivo y tal como él es precisamente para mí." (Husserl, 1986: 58). 
mundo, la consciencia se despliega en diferentes grados o sentidos, cada uno de los cuales comporta a su vez complejas redes de fenómenos irreductibles a sus elementos componentes.

Esta compleja red de fenómenos puede abordarse por grados. En primer lugar es el mundo circundante (Umwelt), como conjunto de fenómenos, lo que forma nuestro espacio vital, horizonte en el que yo como individuo soy el elemento subjetivo. En el mundo circundante formamos parte de los fenómenos, es nuestra vida cotidiana en nuestro cotidiano ser cada uno de nosotros. Esta actitud autorreflexiva, aísla el elemento subjetivo que es llamado por Husserl polo noético. Dice Husserl al respecto:

Empezamos nuestras meditaciones como hombres de la vida natural, representándonos, juzgando, sintiendo, queriendo "en actitud natural". Lo que esto quiere decir nos lo ponemos en claro en sencillas consideraciones, que como mejor las llevamos a cabo es en primera persona.

Tengo conciencia de un mundo extendido sin fin en el espacio y que viene y ha venido a ser sin fin en el tiempo. Tengo conciencia de él, quiere decir ante todo: lo encuentro ante mí inmediata e intuitivamente, lo experimento. Mediante la vista, el tacto, el oído, etc., en los diversos modos de la percepción sensible están las cosas corpóreas, en una u otra distribución espacial, para mí simplemente ahi, "ahi delante" en sentido literal o figurado, lo mismo si fijo la atención especialmente en ellas, ocupándome en considerarlas, pensarlas, sentirlas, quererlas o no. También están seres animados, digamos hombres, inmediatamente para mí ahí; los miro y los veo, los oigo acercarse, estrecho su mano al hablar con ellos, comprendo inmediatamente lo que se representan y piensan, qué sentimientos se mueven en ellos, qué desean o quieren. También ellos están ahí delante, en mi campo de intuición, como realidades, incluso cuando no fijo la atención en ellos (1995: 64). 
El mundo circundante que está ahí delante y del que yo mismo soy miembro, no es un mero agregado de cosas, sino sobre todo es un mundo de valores y de bienes, un mundo práctico. A este mundo se refieren los múltiples movimientos espontáneos de la consciencia cuando emprende una investigación, una descripción o una inferencia, pero también cuando son los multiformes actos y estados del sentimiento y del querer, del alegrarse y el entristecerse, los que tienen lugar. Este mundo que se ofrece a la actitud natural es el que Husserl coloca entre paréntesis, junto con todas las teorías y ciencias que a este ámbito se refieren. Pero como la constitución del mundo lleva a suponer la de los otros yoes, la de otras idénticas estructuras noéticas que poseen la misma propiedad que yo de referirse a las cosas con idéntico sentido, los diversos mundos circundantes subjetivos entran entonces en contacto para conformar un mundo objetivo.

Así, en segundo término se plantea la noción de mundo objetivo en general como el sentido de realidad que tiene una época, en este ámbito somos interlocutores junto con otras subjetividades. El plano intersubjetivo, el mundo en general que engloba las posibilidades de lo real es el horizonte que en esta esfera se está planteando. Un cambio de época sobreviene cuando cambia el sentido de realidad.

El sentido de ser mundo objetivo se constituye sobre el trasfondo de mi mundo primordial en muchos grados. Como primer grado hay que destacar el grado de la constitución del otro o de los otros en general, esto es, de los egos excluidos de mi concreto ser propio [...] Lo extraño en sí primero (el primer no-yo), por lo tanto, es el otro yo. Y esto posibilita la constitución de un nuevo ámbito infinito de lo extrańo, de una naturaleza objetiva y de un mundo objetivo en general, al que pertenecen todos los otros y yo mismo. Está implícito en la esencia de esta constitución, que se eleva a partir de los puros otros [...], el hecho de que los otros para mí 
no permanecen aislados, sino que, por el contrario, constituyen [...] una comunidad de yoes, que me incluye a mí mismo, como una comunidad de yoes que existen los unos con y para los otros, y en última instancia una comunidad de las mónadas, en cuanto comunidad que [...] constituyen el mundo único idéntico (Husserl, 1986: 169).

Husserl da cuenta aquí de la constitución de un mundo objetivo en general, suponiendo para ello la existencia de una comunidad que intersubjetivamente configura tal objetividad. Dicha comunidad es el nosotros a partir del cual se puede hablar del mundo como correlato ideal de una experiencia intersubjetiva. La primera persona del plural es la intersubjetividad, cuyos sujetos individuales están provistos de una facultad constituyente de sentido, una armonía monádica en el más pleno sentido leibniziano.

Finalmente Husserl habla del mundo del conocimiento o mundo de la ciencia, ámbito en el cual los fenómenos que constituyen este horizonte escapan a nuestra representación directa, pareciendo extrańos o ajenos a las preocupaciones más urgentes que caracterizan la vida de los hombres. Extrañamiento frente al cual la filosofía debe tomar una posición muy clara.

La fenomenología tiene que llegar por sí misma a los sistemas de conceptos que determinan el sentido fundamental de todos los ámbitos científicos. Estos son los conceptos que predelinean todas las demarcaciones formales de la idea-forma de un posible universo del ser en general y, por tanto, también la de un posible mundo en general. De acuerdo con esto ellos tienen que ser los auténticos conceptos fundamentales de todas las ciencias [...]. Así, pues, las investigaciones relativas a la constitución trascendental de un mundo [...] no son nada más que el comienzo de una aclaración radical del sentido y del origen (o bien, el sentido a partir del origen) de los conceptos mundo, naturaleza, espacio, tiempo, esencia 
animal, psique, cuerpo orgánico, comunidad social, cultura, etc. Es claro que la efectiva realización de las investigaciones indicadas tendría que conducir a todos los conceptos que, sin ser elucidados, cumplen las funciones de conceptos fundamentales de las ciencias positivas, pero que en la fenomenología surgen con una claridad y distinción universales, que ya no dan lugar a ninguna cuestión concebible (Husserl, 1986: 228-229).

En palabras de su fundador, de la fenomenología surgen las ciencias en tanto ramificaciones suyas, la fenomenología es la verdadera ontología porque encierra en sí todas las posibilidades regionales del ser. Esta ontología general es el universo de fundamentación posible porque el ser primero en sí, que precede a toda objetividad, es la intersubjetividad trascendental, el todo de las mónadas que se asocia en comunidad de distintas maneras.

La filosofía debe situarse en el mundo de la vida cotidiana como reflexión sobre las condiciones en que se da toda experiencia, la filosofía no es ni puede ser una actividad cognoscitiva, sino esencialmente un impulso reflexivo. Esto explica por qué la ciencia trabaja para reducir su asombro inicial, la filosofía, para ampliarlo. Mientras que las ciencias explican, la filosofía comprende, su objeto de estudio es lo real como despliegue de fenómenos. Para Husserl, la ciencia erróneamente parte del supuesto de que los "objetos" a los cuales se aboca, ya existen de antemano, pasando por alto que la mera descripción del objeto, e incluso la elaboración de los conceptos para describirlo son ya intencionales, y estas intencionalidades son inherentes al propio desencadenamiento de fenómenos.

Para comprender la actividad de la consciencia, Husserl utiliza el concepto de intencionalidad, término acuńado por Brentano, quien propuso una psicología no mecanicista, sino una psicología intencional. Husserl desarrolla el concepto diciendo que todo comportamiento humano posee una intencionalidad, una direc- 
ción que la consciencia toma. De tal forma que no tiene sentido hablar de consciencia pura, autónoma, originaria, toda consciencia es consciencia de algo; los verdaderos actos de consciencia están determinados por dirigirse a algo, incluso cuando la consciencia se ocupa de sí misma. En el proceso expositivo del conocimiento, la consciencia es el polo noético del fenómeno y esta posibilidad que tiene la consciencia de hacerse cargo de sí misma situándose fuera de las cosas, es resultado de la fenomenología trascendental. La fenomenología trascendental consiste en ese proceder metódico que permite aislar no sólo la subjetividad, sino llevar a cabo el esclarecimiento de cualquier oportunidad de un conocimiento objetivamente válido, de un conocimiento que es subjetivo pero atañe a un ser independiente de la subjetividad. Mediante dicha reducción fenomenológico-trascendental, la reflexión filosófica alcanza la realidad apodíctica del yo puro y sus contenidos de consciencia. Al abstenernos de seguir el impulso natural que nos lleva a conferir una realidad independiente al mundo óntico, al efectuar la reducción fenomenológico-trascendental, no nos queda más que el soporte de este mundo en la consciencia: el sujeto pensante.

Paralelamente, el contenido de los actos de consciencia es el polo noemático, esencial también para la consciencia, pues mediante la determinación de los objetos se determina el sujeto mismo, la propia interioridad. Lo real se compone de estos procesos, donde los sujetos y los objetos son síntesis de fenómenos, síntesis de múltiples intenciones cuyos componentes son: el polo subjetivo (noésis), el polo objetivo (noema) y la unidad de ambos (intencionalidad). El conocimiento y todos los actos de consciencia se articulan como una actividad dialogante entre ellos. ${ }^{6}$

\footnotetext{
6 "La noesis, o lado noético de lo vivido por la consciencia, es la presencia activa del sujeto en la elaboración de una percepción, en la constitución de una significación; el yo es a la vez receptivo y donador de un solo y mismo movimiento. El noema, o lado noemático de lo vivido, es el resultado de la actividad dialogante de la noesis: el objeto
} 
Sin embargo, los hombres no somos explicables tan sólo a partir de dicho análisis, los hombres no somos entes ni sustancias, sino el sedimento de algo unitario y complejo: el conjunto de todas nuestras vivencias. La vivencia es el estado en que nosotros nos encontramos con el mundo existiendo de una manera peculiar, el mundo se nos enfrenta, nos sale al encuentro. Mientras los demás entes están en el mundo, nosotros nos encontramos con él en determinadas circunstancias, pero vivimos también con el conocimiento de que vamos a morir, por eso cada instante de nuestra existencia es peculiar. Nuestra existencia como unidad que fluye, está determinada por el sido, lo que nos define es nuestra historia, somos lo que hemos sido. Inevitablemente somos nuestra historia porque no podemos vivir el instante presente como presente, sino siempre en función del sido. Esto se debe a que nosotros vivimos el mundo y en cada instante de nuestra historia experimentamos la vida como conjunto, actuando, sepámoslo o no, como una intrincada totalidad temporal.

Una vivencia es entonces esa condición en que sabemos que nos estamos jugando la existencia entera, de tal suerte que cada que actuamos o experimentamos algo, al mismo tiempo nos experimentamos a nosotros mismos sabiendo que lo somos. Vivimos en primera persona, nos tenemos presentes cada que actuamos $y$, puesto que la existencia se juega en esta primera persona, sólo el individuo existe, los demás entes viven. Hemos arribado aquí al umbral de la filosofía contemporánea, al momento de la autorreflexión fenomenológica, al planteamiento de que somos tiempo, no un transcurrir en el tiempo sino tiempo mismo. Justamente por ello, nuestra vida tiene como lo más próximo la muerte.

o sentido constituidos, considerados en su dependencia esencial con respecto al acto constitutivo. Que noesis y noema sean indisociables y se compenetren, es la evidencia misma y la esencia de la intencionalidad." (Robberechts, 1968: 83). 
Para la fenomenología, lo humano es la vivencia entendida como el modo de ser del hombre. En el mundo de la vida se encuentra nuestra peculiaridad ontológica que define cada instante no como suma de estímulos sino como vivencias, como unidades temporales concentradas en rescoldos o sedimentos que duran. Desde este emplazamiento se expone el problema de la vida individual y de la sociedad humana. Para ocuparse de este vivir en primera persona, Husserl utiliza el término Nullerscheinung ${ }^{7}$ para designar precisamente la cualidad espacial que caracteriza el propio cuerpo de estar en el centro del espacio, en un lugar cero del espacio que lingüísticamente llamamos el aquí y respecto al cual todos los otros lugares o modos de aparición serán ahí. Empero, cabría hipotéticamente la posibilidad de abandonar dicho centro, pues todo sujeto empírico puede tener experiencia de otro sujeto en cuanto sujeto, en la medida en que pueda ponerse en lugar del otro analógicamente, introyectándose en él para comprenderle desde dentro.

Yo me pongo en el lugar del otro sujeto: por empatía capto lo que lo motiva a él, y cuán vigorosamente, con qué fuerza. E interiormente llego a comprender cómo él, puesto que tales y cuales motivos lo determinan con tal fuerza, se comporta y se comportaría, de qué es capaz y de qué no lo es. Puedo comprender muchas correlaciones interiores por haber profundizado de tal modo en él. Su yo está por ello captado: es precisamente yo idéntico de tales motivaciones y de tal modo dirigidas y con tal fuerza (Husserl, 1997: 322).

Se podría decir entonces que en la fenomenología éste es el procedimiento adecuado para alcanzar el objetivo planteado por Hus-

7 Término traducido como fenómeno cero (null = cero, erscheinung $=$ fenómeno). Concepto que permite dar cuenta de nuestra condición como seres corpóreos, condicionados a actuar y pensar a través del cuerpo, a partir del punto de vista de cada individuo, lo que representa el punto cero de orientación. 
serl de arribar a un saber firmemente fundamentado gracias a la autorreflexión, logrando así una exposición cabal de las capacidades humanas que posibilitan el conocimiento, para de ahí lanzarse a la crítica del problema histórico-antropológico que el proyecto de la modernidad generó.

Basta con lo dicho para mostrar que el inicial interés epistemológico de Husserl lo conduce a una importante evaluación de la cultura de su época, arrancando de una crítica al psicologismo, Husserl considera que cuando la ciencia se ocupa del hombre, lo hace siempre reduciéndolo a un objeto más de los que constituyen el mundo o como un hecho más en el mundo. La autorreflexión, en cambio, pone de relieve que el hombre con su consciencia es un sujeto racional que se enfrenta al mundo, lo vive e intenta comprenderlo y conocerlo. La razón es así el elemento específico del hombre, en consecuencia, por hombre habremos de concebir un ser cuya vida se despliega en actividades personales. La vida es un devenir constante de la persona misma.

Ver a un hombre no quiere decir todavía conocerlo. Ver a un hombre es -como hemos descubierto- distinto de ver una cosa material. Cada cosa es de una especie. Si conoce uno ésta, está uno listo. Pero el hombre tiene una especie individual, cada uno una distinta. En cuanto a lo general, es hombre, pero su especie caracterológica, su personalidad, es una unidad constituida en la marcha de su vida como sujeto de las tomas de posición, que es unidad de motivaciones variadas sobre presuposiciones variadas, y en tanto que uno conoce líneas análogas por la experiencia de diferentes hombres, puede uno captar "intuitivamente" [intuitiv] la complicación particular y peculiar que está aquí en cuestión y la unidad que aquí se constituye, y tener un hilo conductor para cumplir en la intuición [Anschauung] las intenciones mediante la explanación de los nexos reales. No debe confundirse, pues, a mi entender, esta "intuición" [Intuition] con la intuición [Ans- 
chauung] real. Se trata aquí del acierto de una apercepción que determina con más precisión, la cual, como toda apercepción, ofrece un hilo conductor para confirmar en la marcha de la experiencia nexos intencionales con frecuencia extremadamente complejos (Husserl, 1997: 322).

Si el hombre debe ser definido sobre todo como un ser individual, entonces el nexo de vivencias que le caracterizan no es tan sólo un haz o una mera corriente de consciencia donde las vivencias pueden nadar o ser arrastradas corriente abajo; por el contrario, toda vivencia es de un yo que es persona. En este proceso de autorreflexión, al parecer a fin de cuentas es preciso situarse y decir desde dónde se habla y quien lo hace. Por consiguiente, el término $\mathrm{Nu}-$ llerscheinung, que emplea Husserl para designar la cualidad espacial que caracteriza al propio cuerpo, de estar en el centro del espacio, en un lugar cero del espacio al que llamamos el aqui y respecto al cual todos los otros lugares o modos de aparición serán ahi, es un término que ha permitido a la fenomenología centrar al individuo y hablar de la manera en que ha llegado éste de vuelta a sí, a la autorreflexión. En esta formulación, los ámbitos del mundo circundante y de la intersubjetividad son los que ahora aparecen delineados con especial tonalidad.

Todo lo que es aplicable a mí mismo, sé que es aplicable también a todos los demás hombres que encuentro ahí delante en mi mundo circundante. Teniendo experiencia de ellos como hombres, los comprendo y los tomo como sujetos-yos de los que yo mismo soy uno y como referidos a un mundo circundante natural. Pero esto de tal suerte, que concibo su mundo circundante y el mío como siendo objetivamente un mismo mundo, del que todos nosotros nos limitamos a tener conciencia de diverso modo. Cada uno tiene su lugar desde donde ve las cosas que tiene ahí delante, y por eso se le presentan a cada uno las cosas de diversa manera [...]. 
Acerca de todo esto nos entendemos con los prójimos, poniendo en común una realidad espacial y temporal objetiva como el mundo circundante de todos nosotros, que está ahi y al que pertenecemos nosotros mismos (Husserl, 1995: 68).

Según Szilazi (1973: 28-29), con Husserl el concepto de sujeto adquiere una significación mucho mayor de la que se alcanza cuando llanamente se lo confronta con objetos; la subjetividad es la manera de ser de un ente particular, al que tenemos que llamar sujeto, no en oposición y en relación con objetos exclusivamente, sino atendiendo a la organización de sus capacidades. La subjetividad faculta a este ente particular para conocer, actuar y crear, le capacita, en fin, para tener un mundo que él constituye según sus propios esquemas. Gracias a una autorreflexión radical, la fenomenología puede describir las actividades de la consciencia, utilizando como hilos conductores los diferentes actos particulares de la consciencia misma y dando cuenta así de los fenómenos. Sin embargo, sólo a través de la intersubjetividad es posible la experiencia de un mundo que se despliega en el acuerdo general entre subjetividades.

Para Husserl, jamás hay persona sino entre personas. Este mundo está hecho de interacciones recíprocas; en él cada uno es indiscerniblemente causa y efecto, de la familia a la humanidad entera, pasando por todos los clubes y asociaciones culturales, religiosas, lucrativas o políticas. Mucho más que las cosas, son estas sociedades y sus acontecimientos las que forman el horizonte, o más bien la trama misma, de nuestra vida (Robberechts, 1968: 68).

Si lo que constituye el trasfondo de nuestra vida es la interacción con otras individualidades, cabría afirmar que para Huserl el ser humano es ante todo un proyecto, y que nuestro privilegio de humanos es ser la expresión de aquello que somos, ya que de la infinidad de fuerzas que la atraviesan, la consciencia hace sus propias 
fuerzas y les da valor y sentido. Pero como el ser humano vive en un ámbito social, en un espacio que comparte con otros, el individuo es por tanto elemento de una colectividad que se materializa no sólo en presencia de seres humanos, sino en la cultura que nos rodea y que nos remite a otras generaciones. Este interés de Husserl por las generaciones pasadas y por conducir la reflexión hacia la cultura, abrirá una importante vía de discusión. La subjetividad entonces es temporal y social, esto es, intersubjetiva y necesariamente situada en un cuerpo, por ende la subjetividad es histórica.

Mas, ¿̇cómo es que a través de la constitución de la intersubjetividad se edifica el mundo que experimentamos? Para nuestro autor la clave hay que rastrearla en el pensamiento de Leibniz y su idea de una armonía preestablecida entre las mónadas, Husserl comprende al ego puro como una unidad cerrada en sí misma, como una mónada que tiene la posibilidad de comunicarse con las demás gracias a la armonía preestablecida. Hay, según Husserl, una multiplicidad abierta de yoes puros (o de sus corrientes de consciencia), separados monádicamente unos de otros, que están unificados por empatía mutua en un nexo constituyente de objetividades intersubjetivas.

En primero y en último lugar, toda cosa que experimento está constituida para mí, justamente mediante las vivencias del experimentar, como cosa en el mundo espacio-temporal, y por indeterminada que sea esta posición, por infinitamente múltiple lo que deja abierto, lo deja abierto conforme al sentido de esta apercepción; lo que se capta en la marcha de la experiencia continua se presenta como cumplimiento de motivaciones ya existentes que sólo en el interior de la unidad del sentido se enriquecen y delimitan. Y lo que vale para la constitución de una cosa cualquiera, vale también a priori, en correspondencia con la estructura óntica del nexo de cosas que converge en la unidad del orbe, precisamente para la constitución de este orbe. Éste se constituye necesariamente, [...] de tal manera que, a pesar de la circunstancia de que el yo 
puro es centro de toda intencionalidad en general, el yo empírico, en la forma del yo-hombre, funciona como miembro central fenomenal-real para la constitución aparicional del mundo espaciotemporal en su totalidad: para toda experiencia de la objetividad espacio-temporal está presupuesta la co-aparición del HOMBRE que experimenta, pero también, en efecto, la referencia aperceptiva a la co-aparición de sus prójimos (o animales próximos) reales o posibles (Husserl, 1997: 146-147).

Siguiendo la cita precedente, con Husserl el yo se ha desplegado en diferentes sentidos, encontramos un yo puro, un yo hombre, un yo real, un yo espiritual, un yo personal, un yo psicológico, pero es en este juego libre de las facultades entre yo y otros, donde finalmente se decide todo. Para Husserl el ser humano individual debe considerarse como miembro actuante en la unidad de la comunidad. En consecuencia, la idea de razón no es una idea meramente individual, sino una idea de comunidad. La razón, dice Husserl, es un título vasto que reclama una filosofía auténtica, en donde ninguna verdad particular debe ser absolutizada y donde todo punto de vista unilateral debe poder ser remontado. Para tal efecto, la reflexión husserliana se declara en contra del objetivismo que se manifiesta tanto en las filosofías de la antigüedad como en las de la época moderna, entendiendo por objetivismo o naturalismo aquella actitud vuelta hacia el mundo circundante que concibe todo lo espiritual como algo sobrepuesto a la corporeidad física. Dicho objetivismo no es otra cosa que ingenua unilateralidad; la ciencia objetivista toma lo que ella denomina "el mundo objetivo", y haciéndolo pasar por el universo de todo lo existente, ignora que la subjetividad creadora de la ciencia no puede hallar cabida en ninguna ciencia objetiva de este tipo. Según Husserl, con el olvido del factor subjetivo se ha olvidado también al sujeto actuante y con ello el hombre de ciencia no se convierte en tema de reflexión. Los hombres de ciencia se presuponen a sí mismos como seres humanos que viven 
en la comunidad de su mundo circundante y de su época histórica, prejuicio que impide que el yo que obra y padece, pueda ser convertido en tema de reflexión por la propia ciencia

Frente a toda postura objetivista que toma como punto de partida el absoluto de los hechos, la propuesta husserliana estipula que sólo el espíritu existe en sí mismo y para sí mismo, que sólo el espíritu es autónomo y que incluso la naturaleza verdadera, en su sentido científico natural, es obra del espíritu que la explora. Así, sólo cuando el espíritu retorna de la ingenua orientación hacia lo exterior y se dirige a sí mismo y permanece consigo mismo, puede el espíritu bastarse. Pero, ¿cómo se llegó a tal autorreflexión? La respuesta a esta interrogante tiene que ver con la nueva orientación que la filosofía habrá de tener con el autor que aquí hemos tratado de exponer.

La fenomenología trascendental permitió a Husserl el desarrollo de un método para comprender, en su intencionalidad, la esencia fundamental del espíritu. La fenomenología supera con esto al objetivismo porque es un método en el cual el filósofo parte de su yo, considerándose como el ejecutor de todos sus actos. La filosofía es entonces una actitud que reedifica una ciencia del espíritu absolutamente autónoma y que hace posible a su vez una comprensión del mundo como obra del espíritu humano en su conjunto. En la actitud fenomenológica, el yo ya no es una cosa aislada al lado de otras cosas similares dentro de un mundo dado de antemano. En la investigación fenomenológica sobre la constitución, tanto la exterioridad como la yuxtaposición de los yoes personales, pierden sentido, dando lugar a una relación íntima entre los seres que son el uno con el otro y el uno para el otro. La fenomenología da cuenta de la universalidad del espíritu que abarca todo lo existente; universalidad donde la naturaleza se sitúa como obra del espíritu, puesto que el espíritu es sobre todo actividad creadora. Con estos planteamientos, la crisis de la modernidad es explicada por 
la absorción de la razón dentro del objetivismo, ante lo cual sólo quedan, según Husserl, dos alternativas: el hundimiento total de la cultura, o el renacimiento de la filosofía en la medida en que triunfe sobre el naturalismo u objetivismo.

La filosofía es concebida como condición de posibilidad de una comunidad verdaderamente racional y de una vida auténticamente racional. Husserl consideró que con esto se abría el camino hacia una humanidad nueva y una cultura distinta, pensadas desde la razón filosófica gracias a la cual la humanidad puede comprenderse a sí misma. La filosofía es autorreflexión universal, comprensión del hombre sobre sí mismo; razón que se comprende y se regula a sí misma. Por este motivo, dado que el hombre se construye permanentemente, para Husserl la filosofía es necesariamente un proyecto en marcha.

\section{Bibliografía}

Adorno, T. W., 1986, Sobre la metacritica de la teoría del conocimiento, México, Planeta.

Husserl, E., 1997, Ideas II. Investigaciones fenomenológicas sobre la constitución, México, Unam.

__, 1995, Ideas relativas a una fenomenología pura y una filosofía fenomenológica, México, FCE.

—_, 1986, Meditaciones cartesianas, Madrid, Ediciones Paulinas.

— 1985 , Investigaciones lógicas, Madrid, Alianza Editorial.

_ 1984, Crisis de las ciencias europeas y la fenomenología trascendental, México, Folios Ediciones.

Robberechts, L., 1968, El pensamiento de Husserl, México, FCE.

Szilasi, W., 1973, Introducción a la fenomenología de Husserl, Buenos Aires, Amorrortu. 